\title{
Fountain pen for scanning electrochemical microscopy $\dagger$
}

\author{
Fernando Cortés-Salazar, ${ }^{a}$ Andreas Lesch, ${ }^{b}$ Dmitry Momotenko, ${ }^{a}$ Jean-Marc Busnel, ${ }^{a}$ Gunther Wittstock ${ }^{b}$ \\ and Hubert H. Girault $* a$
}

\author{
Received 8th February 2010, Accepted 28th April 2010 \\ First published as an Advance Article on the web 3rd June 2010 \\ DOI: 10.1039/c0ay00096e
}

\begin{abstract}
A fountain pen probe has been developed to extend the scope of scanning electrochemical microscopy (SECM) experiments to dry surfaces. The fountain pen is fabricated by UV-photoablation of a polyethylene terephthalate (PET) film and consists on one side of one microchannel for flowing an electrolyte solution to the open tip, integrating a reference/counter electrode and on the other side a carbon track. The exposed tip of the track forms the working electrode located close to the microchannel outlet. The fountain pen can operate in a pointillist mode where a nanolitre droplet at the bottom of the probe connects it to a well-defined surface area to study locally the substrate, but can also operate in a scanning mode leaving a linear wet track of solution behind it to monitor the surface activity. The electrochemical characterization of the proposed fountain pen probe was performed by cyclic voltammetry, approach curves and lateral line scans over insulating and conductive substrates, showing that the flow rate and the probe-substrate distance have a major influence on its electrochemical behavior. An SECM image of a gold on glass EPFL logo is presented as a proof-ofconcept that fountain pen probes can be employed for the detection of surface activity when scanning in a contact regime.
\end{abstract}

\section{Introduction}

Recently, a lot of attention has been paid to scanning electrochemical microscopy (SECM), a scanning probe technique, for characterizing the chemical reactivity or topography of surfaces with a high resolution and sensitivity, ${ }^{1-6}$ as well as for performing quantitative kinetic measurements at different interfaces (e.g. liquid/liquid, solid/liquid and gas/liquid). ${ }^{7-16} \mathrm{SECM}$ takes advantage of the fast mass transport at a microelectrode to achieve a steady-state current for the oxidation or the reduction of a present redox mediator. ${ }^{11,17}$ By moving the probe horizontally and measuring the amperometric probe current $i_{\mathrm{T}}$ as a function of horizontal coordinates $(x, y)$, a $3 \mathrm{D}$ image is build, where changes in $i_{\mathrm{T}}$ are directly correlated to the changes in surface activity or topography. Quantitative kinetic information is also obtained from comparing experimental results with numerical simulations of combined mass transport and interfacial kinetic models. ${ }^{7,18-21}$ Therefore, SECM has been successfully applied to the screening of catalysts, ${ }^{22}$ to the study of corrosion $^{23}$ and biological processes ${ }^{24,25}$ and to surface patterning. ${ }^{26-29}$

Additionally, since the SECM positioning system and the micrometre sized probe provide localized electrochemical characterization within areas ranging from $\mathrm{nm}^{2}$ to $\mu \mathrm{m}^{2}$, the study of

\footnotetext{
${ }^{a}$ Laboratoire d'Electrochimie Physique et Analytique, Ecole Polytechnique Fédérale de Lausanne, Station 6, CH-1015 Lausanne, Switzerland. E-mail: hubert.girault@epfl.ch; Fax: +4121-693 3667; Tel: +41 21-6933145

${ }^{b}$ Department of Pure and Applied Chemistry, Center of Interface Science (CIS), Faculty of Mathematics and Natural Sciences, Carl von Ossietzky University of Oldenburg, D-26111 Oldenburg, Germany

$\dagger$ Electronic supplementary information (ESI) available: Details of probe geometry and mounting and further explanation of the probe-substrate distance employed. See DOI: 10.1039/c0ay00096e
}

electrochemical processes occurring at microenvironments can also be performed by SECM. ${ }^{30-32}$ In order to extract reliable information, different constraints have to be considered. On the one hand, the electrochemical cell has to be contained within a microscopic volume, which requires not only the use of small electrodes (i.e. working, reference and counter electrodes), but also a special arrangement of a miniaturized electrochemical cell in such a way that electrode collision does not occur upon scanning. On the other hand, considering that solute concentrations in low volume systems can vary drastically upon solvent evaporation, experimental artifacts may arise and surface modifications have to be minimized (e.g. to avoid precipitation processes).

Micrometer sized electrodes are readily prepared by different techniques, such as by sealing a microwire (e.g. platinum wire or a carbon fiber) either in a glass pipette, in a resin such as epoxy $^{5,33}$ or in an insulating polymer film. ${ }^{34-36}$ Additionally, integrated three ${ }^{37}$ or two $^{31,32}$ electrode cells have been introduced to simplify the electrochemical cell design, to impede collisions between electrodes and to allow an easier positioning of the electrochemical cell. The scanning droplet cell introduced by Lohrengel et al. is based on a three-electrode cell setup, where a capillary containing the reference and counter electrode delivers an electrolyte droplet on a conductive surface. The working electrode is thus defined by the wetted area. ${ }^{37}$ Despite common potentiostatic techniques can be employed with this setup for surface activity studies, it is restricted to the study of conductive substrates. Spaine and Baur reported a positionable microcell supported in a theta glass capillary. ${ }^{31}$ The working electrode located at one of the channels was composed of a carbon fiber sealed with epoxy, while a $\mathrm{Ag} / \mathrm{AgCl}$ wire was positioned as the reference electrode at the other compartment within a concentrated solution of $\mathrm{NaCl}$. This device was 
completed by a salt bridge at the bottom of the pulled glass capillary, which allows the electrical connection and a physical separation between the reference electrode and the analyte solution. Both voltammetric and SECM measurements were performed successfully at subnanolitre volumes. In spite of that, the preparation of this dual probe is cumbersome and a high expertise is required. Additionally, the mechanical stability of the probe is easily compromised by any probe-substrate crash. Another procedure for preparing integrated two electrode microcells was recently introduced by Turcu et al. where a common glass-encapsulated microelectrode was chemically coated with an Ag film and used as reference electrode..$^{32}$ The main advantage of this dual system is the simplicity of the device and its preparation method. Steady-state voltammetry and SECM images of Pt bands in a nanolitre droplet were obtained as a proof-of-concept of the functionality of the proposed dual system. In order to decrease the influence of solution evaporation on the SECM imaging, Turcu et al. covered a nanolitre droplet of the redox mediator solution with a layer of paraffin oil, but with adsorption of this oil onto the microelectrode only between 3 to $4 \%$ of the initial current changes were observed after $50 \mathrm{~min}$ of continuous scanning on a Pt band microarray. With the purpose of avoiding any contamination, special attention has to be paid to the positioning of the redox mediator droplet, the microelectrode and then the covering mineral oil layer. The latter obliges the use of a physical barrier that precludes the paraffin leakage, limiting at the same time the scanned area. The use of a humidity chamber to provide a controlled water-saturated atmosphere or the addition of glycerin to the supporting electrolyte have been also employed with the purpose of decreasing the effect of evaporation on microsystems. ${ }^{31,38-41}$ Recently, Juncker et al. introduces a multipurpose microfluidic probe (MFP) which result from the coupling of microfluidics and scanning probes. ${ }^{42}$ The MFP is based on two apertures placed at the bottom of the device from where solution is injected and aspirated, creating a locally microfluidic flow that covers the sample surface. Taking advantage of microfluidic probes, evaporation problems could be overcome by flowing constantly solution to the gap in between the probe and the sample surface. A similar concept has been already applied in atomic force microscopy (AFM) for surface patterning, where a fluidic channel is introduced into the AFM cantilever, allowing the fluid transport from a reservoir to the end of the cantilever. ${ }^{43-46}$

The present work introduces a fountain pen probe for SECM, fabricated by ablating two parallel and aligned microchannels on opposite sides of a polyethylene terephthalate (PET) sheet. One of the microchannels is filled with carbon ink before coating and the carbon track tip is used as working electrode, while the other is covered by lamination and is used for flowing solution to the tip. An integrated two-electrode cell is completed by a third microchannel filled with $\mathrm{Ag} / \mathrm{AgCl}$ ink and that is in physical contact with the solution flowing through the microchannel. This new probe is based on the same preparation method of the recently developed soft stylus probe, ${ }^{47}$ but introduces a fluidic microchannel and a counter/reference electrode (CE/RE) that may extend the scope of SECM to the scanning of dry surfaces in a contact regime. As a proof-of-concept a gold on glass EFPL logo was imaged by using the fountain pen probe in scanning contact regime.

\section{Experimental}

\section{Chemicals}

Ferrocene methanol $\left(\mathrm{FcCH}_{2} \mathrm{OH}, \geq 97 \%\right.$, Sigma-Aldrich) and $\mathrm{KNO}_{3}(\geq 99 \%$, Buchs, Switzerland) were used as received. Deionized water was produced by a Milli-Q plus 185 model from Millipore (Zug, Switzerland). Fountain pen probes were produced using $100 \mu \mathrm{m}$ thick polyethylene terephthalate films, Melinex (PET, Dupont, Wilmington, DE, USA) and $50 \mu \mathrm{m}$ polyethylene/polyethylene terephthalate (PE/PET, Payne, Wildmere Road, Banbury, England) lamination foils. Laser-machined tracks in PET were filled by Electrador carbon ink (Electra Polymer \& Chemicals Ltd., Roughway Mill, Dunk Green, England) for the working electrode and by $\mathrm{Ag} / \mathrm{AgCl}$ ink (ERCON, Wareham, MA, USA) for the $\mathrm{CE} /$ RE electrode.

\section{Preparation of a gold micro EPFL logo on glass}

Glass slides were treated with piranha solution and cleaned by sequential sonication in ethanol, acetone and purified water followed by drying under a stream of Argon. A gold EPFL logo, $100 \mathrm{~nm}$ thick, was prepared in an Edwards Auto 306 evaporator operating at a pressure less than $5 \times 10^{-6} \mathrm{mbar}$. A metallic mask defined the EPFL logo pattern $(1000 \mu \mathrm{m} \times 1400 \mu \mathrm{m})$. The film growth was initiated by the thermal evaporation of a $1 \mathrm{~nm}$ thick chromium $\left(99.99 \%\right.$, Balzers) layer at $<0.1 \mathrm{~nm} \mathrm{~s}^{-1}$ in order to enhance the adhesion of the Au layer. Gold (99.99\%, Balzers) was subsequently evaporated at $<0.1 \mathrm{~nm} \mathrm{~s}^{-1}$ up to $5 \mathrm{~nm}$, before increasing the deposition rate to $0.2-0.3 \mathrm{~nm} \mathrm{~s}^{-1}$ for the deposition of a $100 \mathrm{~nm}$ layer. An optical picture of the EPFL logo pattern was obtained by using a scanning laser microscope (VK 8700, Keyence).

\section{SECM measurements}

SECM measurements were carried out using a custom-built SECM setup running under SECMx software ${ }^{48}$ and comprising an IVIUM compactstat (IVIUM Technologies, The Netherlands) operating in a classical three-electrode mode or under bipotentiostatic conditions. Data analyses were carried out using MIRA software. ${ }^{49}$ The electrochemical cell comprises $\mathrm{Ag} / \mathrm{AgCl}$ as $\mathrm{CE} / \mathrm{RE}$ and a carbon track as working electrode. All potentials are reported with respect to the $\mathrm{Ag} / \mathrm{AgCl}$ electrode. After polishing, the quality of the electrode was checked with a Laborlux D optical microscope (Leitz, Germany). All the samples were mounted on the bottom of a flat cell construction and investigated at room temperature $\left(20 \pm 2{ }^{\circ} \mathrm{C}\right)$.

For using the new probe in the contact regime, the probe was mounted with a slight tilt with respect to the sample surface thanks to the tapering and the stiffness of the probe. When the probe was pressed against the sample the polymeric probe bends in a way that the cross-section of the carbon track is closer to the sample than the opening of the microfluidic channel (inset of Fig. 3a, later). In order to enable imaging, a new routine was included in the SECMx software that allows examining a surface in contact and contact-less regime during the forward and the backward scanning, respectively. During the forward scan the probe is pressed against the sample, bent, and dragged over it. 
This is possible without damaging the studied surface, if the sample material is harder than the PET sheet from which the probe was made. After completion of the forward scan, the probe is lift off the sample surface by a preset stroke height so that the probe is freely suspended. It is then moved horizontally back to the start position of the line scan followed by an incremental step in the low frequency scan direction. The probe is brought again into mechanical contact with the sample by a vertical translation equal to the negative value of the stroke height and the next line scan in the contact mode commences. Images are constructed from the data acquisition of forward line scans in contact mode. By doing this, the probe bending degree and bending direction are always the same within one image frame when scanning in contact regime.

\section{Fountain pen probe preparation}

Three microchannels were prepared into a polyethylene terephthalate (PET) film by laser ablation through a metallic mask using a $193 \mathrm{~nm}$ ArF excimer laser beam (Lambda Physik, Göttingen, Germany, fluence $=0.2 \mathrm{~J}$, frequency $=50 \mathrm{~Hz}$ ) as reported in previous works. ${ }^{47,50,51}$ The width, depth and length of the prepared microchannels were $35 \mu \mathrm{m}, 40 \mu \mathrm{m}$ and $6.5 \mathrm{~cm}$ for the open microchannel, $15 \mu \mathrm{m}, 20 \mu \mathrm{m}$ and $4 \mathrm{~cm}$ for the working electrode (WE) and $35 \mu \mathrm{m}, 40 \mu \mathrm{m}$ and $2 \mathrm{~cm}$ for the CE/RE. The open microchannel and the one dedicated as WE were aligned at each side of the PET film, while the open microchannel and the one used as $\mathrm{CE} / \mathrm{RE}$ were perpendicularly connected over the same PET face (Fig. 1). Carbon and $\mathrm{Ag} / \mathrm{AgCl}$ inks were applied (manually with a spatula) to create conductive tracks for the WE and $\mathrm{CE} / \mathrm{RE}$, respectively. After curing the conductive tracks at $80{ }^{\circ} \mathrm{C}$ for $1 \mathrm{~h}$, one PE/PET film lamination was applied over the electrode and one underneath. A reservoir was glued at one of the extremities of the open microchannel to allow the connection with an external pumping syringe system (KD Scientific). A cross section of the microchannel was then exposed by mechanical cutting and polishing by successively finer diamond lapping discs (Ultra-prep, Buehler, Schlieren, Switzerland) with different particle sizes of $30 \mu \mathrm{m}, 6 \mu \mathrm{m}$, and $0.1 \mu \mathrm{m}$ using a custom-built polishing machine. In order to avoid the blocking of the fluidic microchannel during the polishing process, it was first filled by capillarity with a saturated $\mathrm{KCl}$ solution that was left to crystallize. Then, the electrode was polished and finally submerged in

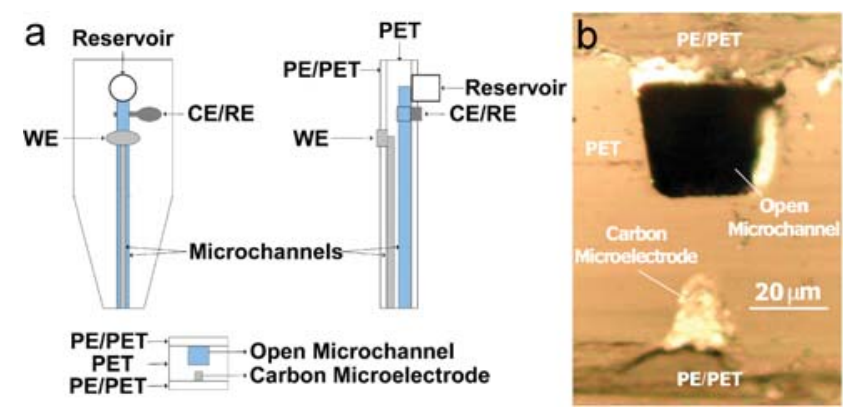

Fig. 1 a) Schematic representation of the fountain pen probe used as working electrode for SECM; b) optical image of the carbon electrode exposed by mechanical polishing. water for $4 \mathrm{~h}$ until the $\mathrm{KCl}$ was totally dissolved and the electrode was ready to use.

\section{Results and discussion}

Fig. 1a shows a schematic representation of the fountain pen probe prepared by the method presented above. As it can be seen the fountain pen probe integrates a two electrode system, where the electrical connection between the WE and the CE/RE is made by the solution that is flowing through the open microchannel. From Fig. 1b it is possible to see the good parallel alignment between the open microchannel (thickness $=35 \mu \mathrm{m}$, width $=$ $40 \mu \mathrm{m}$ ) and the microelectrode (thickness $=20 \mu \mathrm{m}$, width $=$ $15 \mu \mathrm{m})$. The microchannel prepared for the working electrode is almost completely filled with carbon ink. The working electrode has a trapezoid-like shape defined by the cross-section of the prepared microchannel, which can be easily reproduced.

The electrochemical characterization of the fountain pen probes was performed by cyclic voltammetry, approach curves and horizontal line scans over conductive and insulating substrates. Before each experiment, an aqueous solution of $\mathrm{FcCH}_{2} \mathrm{OH}$ in $\mathrm{KNO}_{3}$ was allowed to flow out until a drop of the solution covered completely the tip of the electrode and made a physical contact with the substrate (see inset in Fig. 2a and Fig. S1, ESI $\dagger$ ). Fig. 2a presents the cyclic voltammogram of $\mathrm{FcCH}_{2} \mathrm{OH}$ at a fountain pen probe at a flow rate of $25 \mu \mathrm{L} \mathrm{h}^{-1}$ and $0 \mu \mathrm{L} \mathrm{h}^{-1}$. Since the electrode was placed around $500 \mu \mathrm{m}$ above the sample, a steady state bulk situation can be assumed. The steady state currents obtained for both cases results from the pseudo-hemispherical diffusion present at the microelectrode. Despite the very low charging current observed, the slope of the rising part of the curve is lower than expected for a reversible redox couple due to a high ohmic drop between the CE/RE and the WE. This can be overcome by increasing the concentration of the supporting electrolyte, increasing the area of the CE/RE electrode and by reducing the actual separation distance between these two electrodes (i.e. $4 \mathrm{~cm}$ ). According to Fig. 2a, the flow rate has little influence on the cyclic voltammetry when the electrode is located far away from the substrate, the small increase observed at $25 \mu \mathrm{L} \mathrm{h}^{-1}$ being most likely due to an enhanced mass transport.

Approach curves at a flow rate equal to $25 \mu \mathrm{L} \mathrm{h}^{-1}$ over an insulating glass and a conductive gold film were performed resulting in the curves shown in Fig. $2 b$ (continuous lines), and compared qualitatively to approach curves (dashed lines) obtained in the same conditions, but using the carbon working electrode immersed classically in the electrolyte above the substrate. The latter case corresponds to the recently developed soft stylus probe. ${ }^{47}$ As expected a decrease of the current is recorded when the soft stylus probe is approached to an insulating substrate, while a current increase is observed when it is approached towards a conductive surface. In contrast, the fountain pen probe gives a continuous increase of the current profile in approach curves both, over glass or over gold. This is due to the fact that the blocking of the redox mediator diffusion is counterbalanced by the solution flux out of the microfluidic channel. Moreover, it has to be taking into account that the lateral flux to the electrode surface will become faster as the probe is located closer to the surface. As a consequence, an 

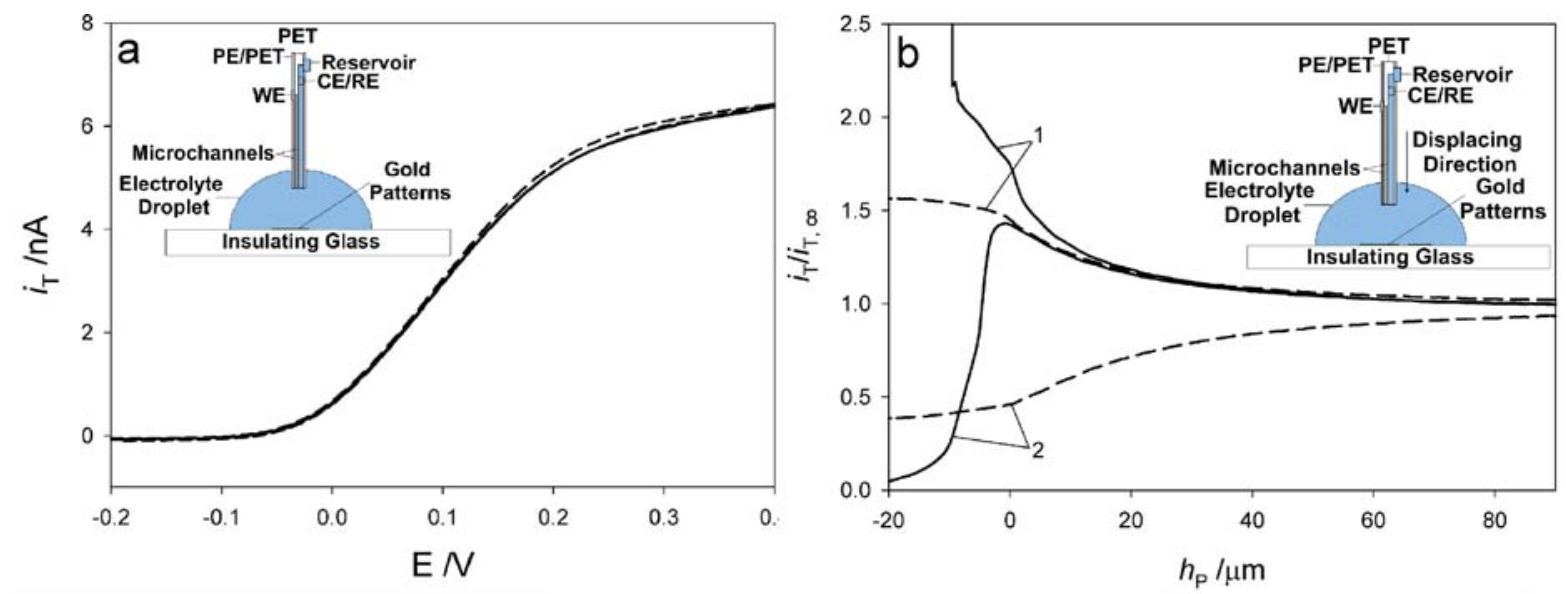

Fig. 2 a) Cyclic voltammetry at a fountain pen probe in $3.14 \mathrm{mM} \mathrm{FcCH}_{2} \mathrm{OH}$ and $0.1 \mathrm{M} \mathrm{KNO}_{3}$ at a flow rate of $25 \mu \mathrm{L} \mathrm{h}{ }^{-1}$ (dashed lines) and $0 \mu \mathrm{L} \mathrm{h}^{-1}$ (continuous line). Scan rate $10 \mathrm{mV} \mathrm{s}^{-1}$. b) Experimental approach curve of a fountain pen probe (continuous line) and a soft stylus probe (dashed line) over unbiased gold electrode (1) and insulating glass (2). $E_{\mathrm{T}}=0.40 \mathrm{~V}$, translation rate $=0.5 \mu \mathrm{m} \mathrm{s}^{-1}$ and flow rate $=25 \mu \mathrm{L} \mathrm{h}{ }^{-1}$. The insets in Fig. $2 \mathrm{a}$ and $2 \mathrm{~b}$ show the conditions in which the experiments were performed.

enhanced positive feedback behavior is observed. When the soft stylus probe touches the substrate surface, the probe is bended and the current changes as a function of the bending. It should be noted that the probe-sample distance change starts to differ distinctly from the vertical position change of the positioning system when the electrode physically touches the substrate. For this reason, the distance measured from the surface to the lowest point of the fountain pen $\left(h_{\mathrm{P}}=h_{\mathrm{A}}-l_{\mathrm{T}}\right)$ was defined as the difference between the height of the attachment point of the fountain pen with respect to the sample surface $\left(h_{\mathrm{A}}\right)$ and the length of the probe in the unbent state $\left(l_{\mathrm{T}}\right)$. When the probe is pressed against the surface a tilt angle $(\alpha)$ between the sample surface and the probe will be established. Thus $d$ is completely defined by $d=h_{\mathrm{P}}+t_{\mathrm{L}} \sin (\alpha)$, where $t_{\mathrm{L}}$ is the thickness of the polymeric film that is between the sample surface and the carbon electrode (see Fig. S2, ESI $\dagger$ ) ${ }^{47}$ When the fountain pen probe is closer to the insulating glass, a more efficient blocking of the redox mediator diffusion is achieved. As a result, the redox mediator flux that is coming from the open microchannel is overcome and a decrease of the current is observed until the probe starts to be bended and the current does not depend anymore strongly on the vertical position of the positioning system. Conversely, an increase on the current takes place when the fountain pen probe is approached to the gold film as expected from positive feedback in conventional SECM setups. It should be noted that the fountain pen can cause positive feedback although the sample potential is not externally controlled. This can be expected if the area on the sample wetted by the electrolyte is substantially larger than the active electrode area of the fountain pen probe. In this situation a concentration cell can be established between the sample areas in the vicinity of the probe and more distant wetted regions on the conducting sample regions. ${ }^{52}$ The fact that the fountain pen probe presents a stronger positive and negative feedback than the soft stylus probe $^{47}$ is explained by a more parallel alignment between the active electrode area and the substrate.
From Fig. 2b, it can be observed that for detecting of surface activity, the fountain pen probe must be used in a contact regime, where the highest current contrast is achieved. This is confirmed by performing lateral line scans over a glass-gold boundary at different $h_{\mathrm{p}}$ values (Fig. 3a, all the scans were aligned according to the observed position of the glass-gold boundary). When the probe is at $10 \mu \mathrm{m}$ from the substrate, no current difference is observed between the insulating and the conductive substrates. At $h_{\mathrm{P}}$ equal to $-10 \mu \mathrm{m}$ and $-20 \mu \mathrm{m}$, a current contrast between the insulating and conductive regions is observed as the blocking of the redox mediator diffusion or its recycling can not be shielded by the flowing solution. It is expected that the fountain pen probe is not limited to work in contact regime, since it might be also employed in a contact-less regime for micro-structuring and patterning of dry surfaces.

In contrast to the bulk-like situation (Fig. 2a), the flow rate has an important effect on the steady state currents, when the probe is in close contact with the otherwise dry substrate (Fig. 3). When the probe is approached to a conductive substrate, a slightly higher current increase is observed for lower flow rates (Fig. 3b). The latter might be explained by a lower dilution factor of the redox mediator concentration when lower flow rates are employed. In contrast, when approaching the probe to an insulating substrate, lower currents are recorded as lower flow rates are employed. This phenomenon is a consequence of a faster depletion on the redox species concentration, when less species are delivered to the gap in between the probe and the sample surface. Therefore, higher current contrast between active and non-active surfaces should be obtained when scanning with the fountain pen probe at lower flow rates, as it is confirmed in Fig. 3c. Fig. 3c shows several lateral line scans over a glass-gold boundary with a fountain pen probe working in contact regime $\left(h_{\mathrm{P}}=-20 \mu \mathrm{m}\right)$ for three different flow rates. Despite a better current contrast with a flow rate of $5 \mu \mathrm{L} \mathrm{h}^{-1}$, evaporation processes started to become crucial, since microchannel blocking by electrolyte precipitation took place. Flow rates values higher 

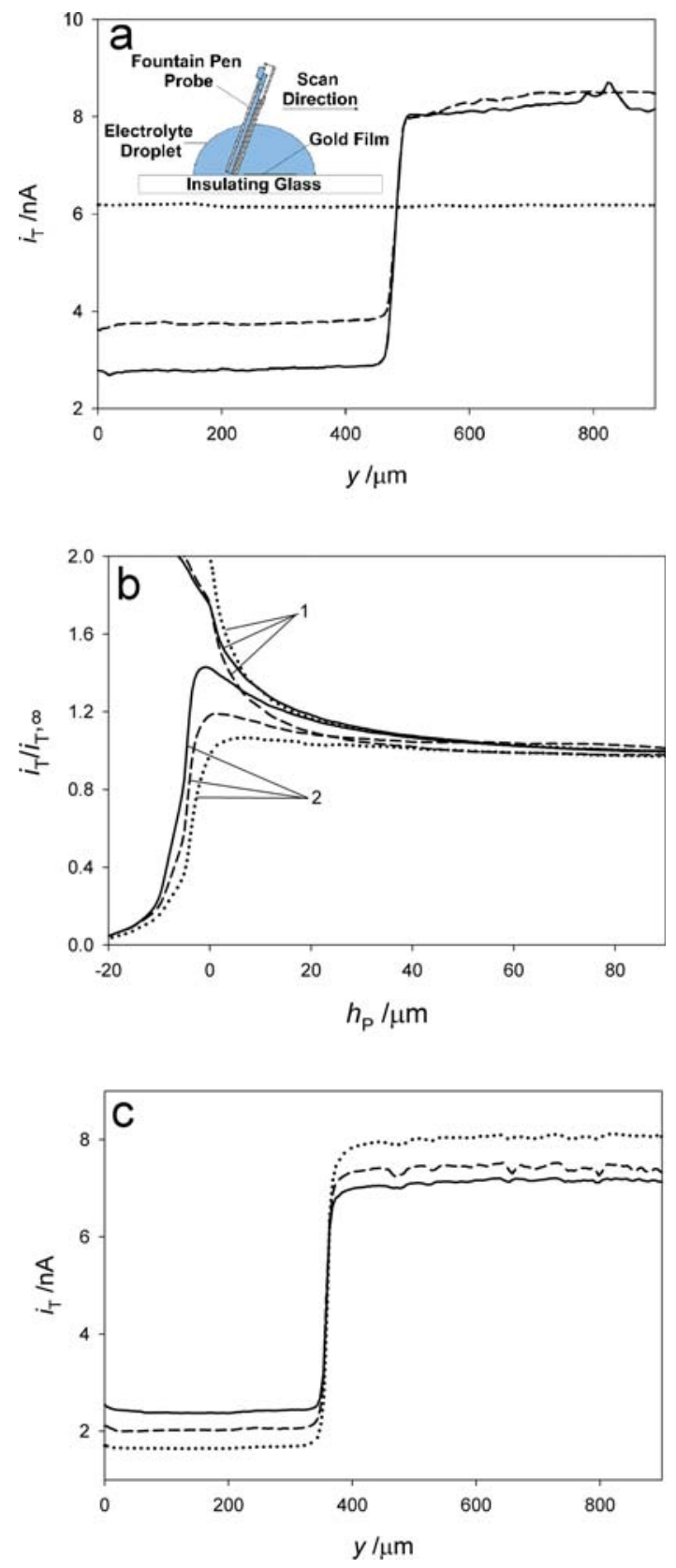

Fig. 3 a) Lateral SECM line scans in feedback mode with a polished fountain pen probe over a glass partially covered by gold at a $h_{\mathrm{P}}$ value of $10 \mu \mathrm{m}$ (pointed line), $-10 \mu \mathrm{m}$ (dashed line) and $-20 \mu \mathrm{m}$ (continuous line). $E_{\mathrm{T}}=0.4 \mathrm{~V}$, flow rate $=25 \mu \mathrm{L} \mathrm{h}^{-1}$, step size $=5 \mu \mathrm{m}$ and translation rate $v_{\mathrm{T}}=25 \mu \mathrm{m} \mathrm{s}^{-1}$. $2.1 \mathrm{mM} \mathrm{FcCH}_{2} \mathrm{OH}$ with $0.1 \mathrm{M} \mathrm{KNO}_{3}$. b) Experimental approach curves of a fountain pen probe over unbiased gold electrode (1) and insulating glass (2) at a flow rate of $25 \mu \mathrm{L} \mathrm{h}^{-1}$ (continuous line), $15 \mu \mathrm{L}$ $\mathrm{h}^{-1}$ (dashed line) and $5 \mu \mathrm{L} \mathrm{h}^{-1}$ (pointed line). $E_{\mathrm{T}}=0.4 \mathrm{~V}$, translation rate $0.5 \mu \mathrm{m} \mathrm{s}^{-1}$. $2.1 \mathrm{mM} \mathrm{FcCH}_{2} \mathrm{OH}$ with $0.1 \mathrm{M} \mathrm{KNO}_{3}$. c) Lateral SECM line scans in feedback mode with a fountain pen probe over a glass partially covered by gold at a flow rate of $25 \mu \mathrm{L} \mathrm{h}^{-1}$ (continuous line), $15 \mu \mathrm{L} \mathrm{h}^{-1}$ (dashed line) and $5 \mu \mathrm{L} \mathrm{h}^{-1}$ (pointed line). $h_{\mathrm{P}}=-20 \mu \mathrm{m}, E_{\mathrm{T}}=0.4 \mathrm{~V}$, step size $=5 \mu \mathrm{m}$ and translation rate $v_{\mathrm{T}}=25 \mu \mathrm{m} \mathrm{s}^{-1} .2 .5 \mathrm{mM} \mathrm{FcCH}_{2} \mathrm{OH}$ with $0.1 \mathrm{M} \mathrm{KNO}_{3}$. The inset in Fig. 3a shows the orientation of the probe during forward scanning. than $25 \mu \mathrm{L} \mathrm{h}^{-1}$ showed delamination of the PE/PET covering films due to the higher pressure required to achieve this flow rate. For this reason, flow rates between 15 to $25 \mu \mathrm{L} \mathrm{h}^{-1}$ are suggested as appropriate flow rates for SECM imaging with the fountain pen.

It is important to recall that evaporation processes are a major issue when working in microvolumes of liquids. To avoid this major drawback, the use of a humidity chamber, the addition of glycerin to the supporting electrolyte and the covering of the aqueous microsystem with a mineral oil, have been proposed. ${ }^{31,32,38-41}$ A different approach can be proposed by using the fountain pen probe, since evaporation processes could be partially counterbalanced by the constant flow of solution from the open microchannel. With the aim of assessing this possibility, an EPFL logo prepared by evaporation through a mask was imaged under dry conditions by using a fountain pen probe in a contact regime (Fig. 4). This image was build by using a new routine included in the SECMx software, that allows to examine a surface in contact and contact-less regime during the forward and the backward scanning, respectively (see experimental part). The experimental time employed for this image was $2.24 \mathrm{~h}$, during which no apparent changes of the recorded current due to evaporation process (i.e. drastically increase on the redox mediator concentration) were observed. The only problem arising from the evaporation of the supporting electrolyte is the deposited material on the sample that actually could affect the degree by which the fountain pen is bended. The latter is most likely the reason for the small shift of the recorded position of the letters "P", "F" and "L" in the bottom part of the image, as
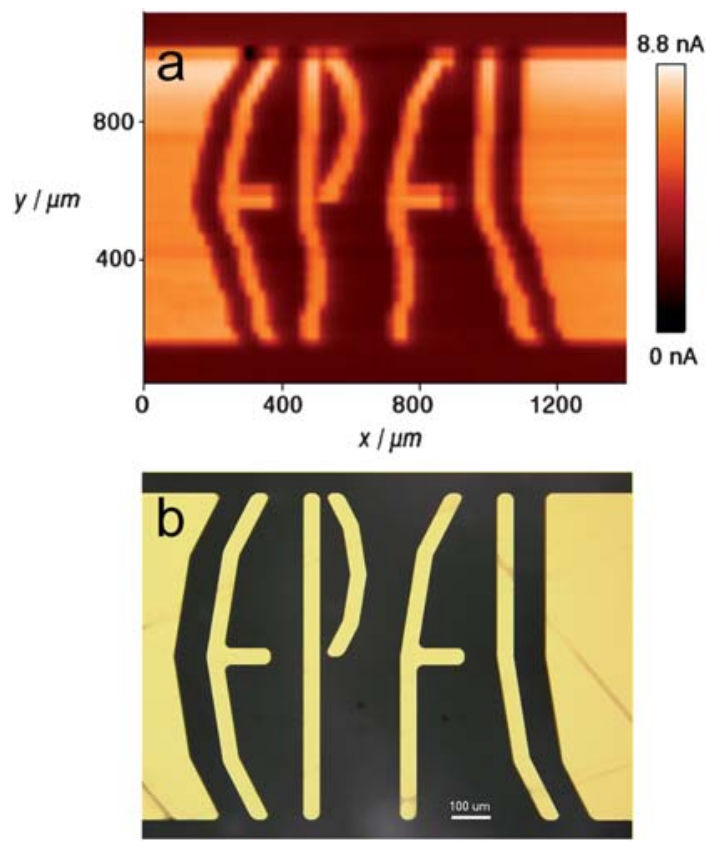

Fig. 4 a) SECM image of a gold micro EPFL logo taken with a polished fountain pen in feedback mode. The fountain pen was lift off after each forward scan by a stroke height of $200 \mu \mathrm{m}$ and placed back at the original vertical position of the scanning but shifted by $20 \mu \mathrm{m}$ in $y$ direction. $h_{\mathrm{P}}=$ $30 \mu \mathrm{m}, E_{\mathrm{T}}=0.4 \mathrm{~V}$, flow rate $=20 \mu \mathrm{L} \mathrm{h}^{-1}$, step size $=20 \mu \mathrm{m}$ and translation rate $v_{\mathrm{T}}=20 \mu \mathrm{m} \mathrm{s}^{-1} .2 .6 \mathrm{mM} \mathrm{FcCH}_{2} \mathrm{OH}$ with $0.1 \mathrm{M} \mathrm{KNO}_{3}$. b) Optical picture of the micro EPFL logo employed for this experiment. 
compared with the optical picture of EPFL logo taken after the SECM image was obtained from this sample (Fig. 4b). Future work will be focused on the removal of the solution that is flowing out from the open microchannel using a push-pull system. Only small scratches on the gold film are observed in Fig. 4b. They were most likely present on the sample before imaging and may arise from handling the samples but not from the scanning movement because they are not parallel to the scanning movement and do not occur in a repetitive manner. This is not unexpected because the gold and other substrate materials are harder than the polymeric material employed for the preparation of the fountain pen probe. In Fig. 4a, the EPFL logo can be clearly observed due to the recycling of the redox mediator obtained over the conductive gold film (positive feedback) and hindered diffusion of the redox mediator over the insulating areas (negative feedback). The SECM image of the EPFL logo shows the feasibility of applying the fountain pen probe to surface activity characterization of dry surfaces. Additionally, the contact regime allows the fountain pen probe to study moderately tilted surfaces without observing any topographical artifacts, as the gold micro EPFL logo was mounted without any attempt of leveling the surface and a tilt would otherwise clearly visible on scan length of $1400 \mu \mathrm{m}$.

\section{Conclusions}

The present work introduced the fabrication of a new fountain pen SECM probe that may extend the scope of SECM to the scanning of dry surfaces in a contact regime by delivering a nanolitre droplet at the bottom of the probe. Electrochemical experiments can be carried out over almost any surface. An optimum flow rate between 15 and $25 \mu \mathrm{L} \mathrm{h}^{-1}$ was obtained for spatially resolved surface activity characterization. Due to the stiffness of the fountain pen probe, an almost constant probesubstrate distance can be maintained when scanning in contact regime. As a proof-of-concept the fountain pen probes can be employed for surface activity detection as demonstrated by a feedback image of a gold on glass pattern. Future experiments are being focused on the extension of this new probe to patterning and micro-structuring of dry surfaces.

\section{Acknowledgements}

The Fonds National Suisse pour la Recherche Scientifique (Grant no 20PA21_121570/1) and Deutsche Forschungs- [LF/ $\mathrm{CR}$ ] gemeinschaft (Wi 1617/10) are thanked for financial support of the binational project "High throughput SECM imaging". The technical assistance by Valérie Devaud is also acknowledged.

\section{References}

1 R. C. Engstrom, Anal. Chem., 1984, 56, 890-894.

2 R. C. Engstrom, T. Meaney, R. Tople and R. M. Wightman, Anal. Chem., 1987, 59, 2005-2010.

3 A. J. Bard, G. Denuault, C. Lee, D. Mandler and D. O. Wipf, Acc. Chem. Res., 1990, 23, 357-363.

4 A. J. Bard, F. R. F. Fan, J. Kwak and O. Lev, Anal. Chem., 1989, 61, $132-138$.

5 A. J. Bard and M. V. Mirkin, Scanning electrochemical microscopy, John Wiley and sons, New York, 2001.
6 P. Sun, F. O. Laforge and M. V. Mirkin, Phys. Chem. Chem. Phys., 2007, 9, 802-823.

7 C. Wei, A. J. Bard and M. V. Mirkin, J. Phys. Chem., 1995, 99, 1603316042 .

8 G. Wittstock, M. Burchardt, S. E. Pust, Y. Shen and C. Zhao, Angew. Chem., Int. Ed., 2007, 46, 1584-1617.

9 Z. Ding, B. M. Quinn and A. J. Bard, J. Phys. Chem. B, 2001, 105, 6367-6374.

10 Y. Selzer, I. Turyan and D. Mandler, J. Phys. Chem. B, 1999, 103, $1509-1517$.

11 A. J. Bard, M. V. Mirkin, P. R. Unwin and D. O. Wipf, J. Phys. Chem., 1992, 96, 1861-1868.

12 A. L. Barker, M. Gonsalves, J. V. MacPherson, C. J. Slevin and P. R. Unwin, Anal. Chim. Acta, 1999, 385, 223-240.

13 P. Sun and M. V. Mirkin, Anal. Chem., 2006, 78, 6526-6534.

14 B. Liu, A. J. Bard, M. V. Mirkin and S. E. Creager, J. Am. Chem. Soc., 2004, 126, 1485-1492.

15 D. Mandler and P. R. Unwin, J. Phys. Chem. B, 2003, 107, 407410.

16 X. Lu, Q. Wang and X. Liu, Anal. Chim. Acta, 2007, 601, 1025.

17 J. Heinze, Angew. Chem., Int. Ed. Engl., 1993, 32, 1268-1288.

18 R. Cornut and C. Lefrou, J. Electroanal. Chem., 2008, 621, 178184.

19 C. G. Zoski and M. V. Mirkin, Anal. Chem., 2002, 74, 1986-1992.

20 Y. Selzer and D. Mandler, Electrochem. Commun., 1999, 1, 569-575.

21 M. A. Edwards, S. Martin, A. L. Whitworth, J. V. Macpherson and P. R. Unwin, Physiol. Meas., 2006, 27, R63, art. no. R01.

22 J. L. Fernandez, D. A. Walsh and A. J. Bard, J. Am. Chem. Soc., 2005, 127, 357-365.

23 S. E. Pust, W. Maier and G. Wittstock, Z. Phys. Chem., 2008, 222, $1463-1517$.

24 S. Amemiya, J. Guo, H. Xiong and D. A. Gross, Anal. Bioanal. Chem., 2006, 386, 458-471.

25 K. B. Holt and A. J. Bard, Biochemistry, 2005, 44, 13214-13223.

26 C. Hess, K. Borgwarth and J. Heinze, Electrochim. Acta, 2000, 45, $3725-3736$

27 I. Turyan, T. Matsue and D. Mandler, Anal. Chem., 2000, 72, 34313435.

28 M. Sheffer and D. Mandler, J. Electrochem. Soc., 2008, 155, D203D208.

29 T. Matrab, C. Combellas and F. Kanoufi, Electrochem. Commun., 2008, 10, 1230-1234.

30 D. O. Wipf, F. Ge, T. W. Spaine and J. E. Baur, Anal. Chem., 2000, 72, 4921-4927.

31 T. W. Spaine and J. E. Baur, Anal. Chem., 2001, 73, 930-938.

32 F. Turcu, A. Schulte and W. Schuhmann, Anal. Bioanal. Chem., 2004, 380, 736-741.

33 C. G. Zoski, Electroanalysis, 2002, 14, 1041-1051.

34 K. T. Kawagoe, J. Jankoswki and R. M. Wightman, Anal. Chem., 1991, 63, 1589-1594.

35 T. G. Strein and A. G. Ewing, Anal. Chem., 1992, 64, 1368-1373.

36 A. Schulte and R. H. Chow, Anal. Chem., 1996, 68, 3054-3058.

37 M. M. Lohrengel, A. Moehring and M. Pilaski, Fresenius J. Anal. Chem., 2000, 367, 334-339.

38 T. M. Day, P. R. Unwin and J. V. Macpherson, Nano Lett., 2007, 7, $51-57$.

39 A. P. Suryavanshi and M. F. Yu, Nanotechnology, 2007, 18, 105305, art. no. 105305.

40 J. C. Ball, D. L. Scott, J. K. Lumpp, S. Daunert, J. Wang and L. G. Bachas, Anal. Chem., 2000, 72, 497-501.

41 C. D. T. Bratten, P. H. Cobbod and J. M. Cooper, Anal. Chem., 1997, 69, 253-258

42 D. Juncker, H. Schmid and E. Delamarche, Nat. Mater., 2005, 4, 622627.

43 A. Lewis, Y. Kheifetz, E. Shambrodt, A. Radko, E. Khatchatryan and C. Sukenik, Appl. Phys. Lett., 1999, 75, 2689-2691.

44 S. Eklund and L. Hedlund, J. Sci. Instrum., 1951, 28, 30.

45 C. Shin, K. Hwang, Y. Kim and H. Kim, Digest of Papers Microprocesses and Nanotechnology 2007, 20th International Microprocesses and Nanotechnology Conference, MNC, 2007, 502503.

46 S. Deladi, N. R. Tas, J. W. Berenschot, J. H. De Boer, M. J. De Boer, G. J. M. Krijnen and M. C. Elwenspoek, Micro Electro Mech. Syst., IEEE Int. Conf., 18th, 2005, 2005, 564-567. 
47 F. Cortés-Salazar, M. Träuble, F. Li, J. M. Busnel, A. L. Gassner, M. Hojeij, G. Wittstock and H. H. Girault, Anal. Chem., 2009, 81, 6889-6896.

48 K. Nunes, K. Hallmeier, R. Szargan, T. Raschke, C. Radehaus and G. Wittstock, Electroanalysis, 2007, 19, 1023-1031.

49 G. Wittstock, T. Asmus and T. Wilhelm, Fresenius J. Anal. Chem., 2000, 367, 346-351.
50 M. A. Roberts, J. S. Rossier, P. Bercier and H. H. Girault, Anal. Chem., 1997, 69, 2035-2042.

51 J. S. Rossier, M. A. Roberts, R. Ferrigno and H. H. Girault, Anal. Chem., 1999, 71, 4294-4299.

52 D. O. Wipf and A. J. Bard, J. Electrochem. Soc., 1991, 138, 469474. 